\title{
Matérias-primas do Planalto de Poços de Caldas: Alternativas ao Caulim e ao Feldspato na formulação de Porcelanas e materiais de Revestimento.
}

\author{
T. Kotania,b, P. M. Nakachima ${ }^{b}$, L. L. H. C. Ferreira ${ }^{b, c}$, A. L. Pereira ${ }^{b x}$ \\ ${ }^{a}$ DEMa, Universidade Federal de São Carlos, São Carlos - SP, Brasil. \\ ${ }^{b}$ Mineração Curimbaba Ltda, Poços de Caldas - MG, Brasil. \\ ${ }^{c}$ Elfusa Geral de Eletrofusão Ltda, São João da Boa Vista - SP, Brasil. \\ *e-mail: andre.pereira@curimbaba.com.br
}

\begin{abstract}
Resumo
Materiais a base de caulim, feldspato e quartzo encontram variadas aplicações na indústria cerâmica, principalmente em formulações de porcelanas e materiais ligados à construção civil, mercados em que o Brasil é destaque internacional. As grandes reservas de rocha potássica e fonolito na região de Poços de Caldas - MG, apresentam-se como potenciais substitutos ao tradicional feldspato devido ao alto caráter fundente. Em adição, argilas desta mesma região também são alternativas frente ao consumo de caulim, substituindo-o parcialmente ou totalmente em formulações cerâmicas. Este estudo apresenta a validade destas alternativas, apresentando formulações cerâmicas e matérias-primas com potencialidades tecnológicas.
\end{abstract}

Palavras-chave: porcelana, rocha potássica, fonolito, argila, Poços de Caldas.

\section{Introdução}

A tecnologia da arte cerâmica através de materiais hoje conhecidos como porcelanas, teve seu início na China do século X, com o desenvolvimento de um material branco de estrutura rígida, com excelentes características técnicas. Tal tecnologia só chegou a ser reproduzida na Europa a partir do século XVII, quando os europeus conseguiram descobrir o segredo dos chineses, e o material ficou conhecido como louças de mesa. O segredo dos chineses residia em dois aspectos principais: formulação e tratamento térmico [1]. O produto era conformado com base em três componentes cerâmicos devidamente misturados [caulim (argila chinesa), sílica (quartzo) e feldspato (mistura de silicatos de alumínio, potássio e sódio)], seguido de tratamento térmico de alta temperatura [1]. Desde então, as porcelanas têm sido produzidas a partir de argila ou caulim, feldspato e quartzo.

A argila confere plasticidade e resistência mecânica a verde, além de formar a mulita $\left(\mathrm{Al}_{6} \mathrm{Si}_{2} \mathrm{O}_{13}\right)$ durante a sinterização [2]. O feldspato é utilizado como fundente, facilitando a formação de fase líquida e possibilitando a formação de um produto com baixa porosidade [2]. No processamento em altas temperaturas, o feldspato decompõe-se em uma fase amorfa e na fase cristalina leucita $\left(\mathrm{KAlSi}_{2} \mathrm{O}_{6}\right)$ em temperaturas próximas de $1.150^{\circ} \mathrm{C}$ [3]. Desta forma, o teor de feldspato determinará a fusibilidade ou o amolecimento da porcelana exposta sob altas temperaturas. Por outro lado, o quartzo gera uma maior estabilidade térmica e dimensional devido ao seu elevado ponto de fusão [2].

A figura 1 mostra diversos produtos de aplicação tecnológica que utilizam diferentes proporções de argila, feldspato e quartzo, a grande parte deles ligado ao mercado da construção civil. No caso de porcelanas, geralmente é utilizado o caulim como tipo de argila, uma vez que ele gera um produto com maior brancura e melhores propriedades mecânicas $[4,5]$.

Desta forma, a formulação das porcelanas e/ou dos materiais de revestimento deve ser feita de modo a apresentar propriedades específicas de processo e produto (plasticidade, sinterabilidade, cor, opacidade, resistência mecânica e à abrasão, tenacidade à fratura, resistividade elétrica e térmica, apenas para citar alguns) conforme o fim desejado. Para fins estruturais, uma baixa porosidade, elevada resistência mecânica e específicas densidades são demandadas.

Em se tratando dos segmentos de cerâmica estrutural, revestimentos e sanitários, temos ainda que estes setores da construção civil ainda são os que mais fortemente contribuem no mercado da indústria cerâmica nacional [7]. O Brasil é um dos principais protagonistas no mercado mundial de revestimentos cerâmicos, ocupando a terceira posição em produção e consumo. Há uma capacidade produtiva instalada de 1.048 milhões de metros quadrados, sendo produzidos 790 milhões em 2017, após ápice de 903 milhões em 2014 [8]. Embora seja o sexto maior exportador mundial, o mercado consumidor é essencialmente doméstico, representando mais de $85 \%$ da produção [8]. O setor é constituído por quase uma centena de empresas, sendo elas concentradas nas regiões sul e sudeste, mais fortemente no estado de São Paulo, e em expansão no nordeste do país, ambas associadas à disponibilidade local de matérias-primas. Uma característica típica da produção brasileira é a utilização de dois processos distintos em seu parque fabril, sendo processamento via 


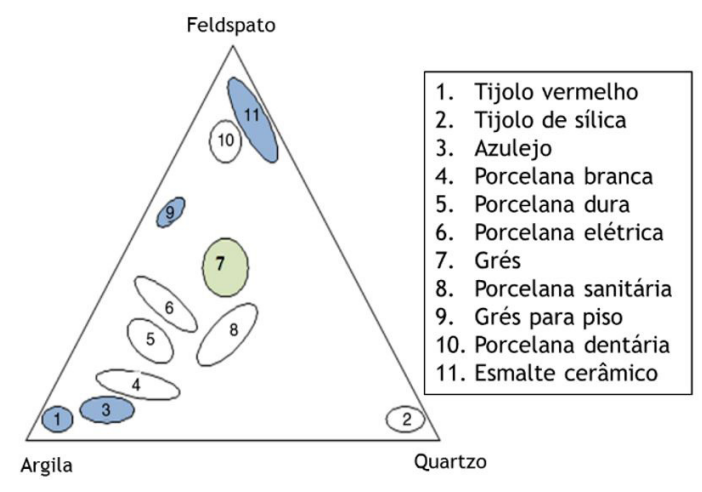

Figura 1. Triaxial cerâmico e suas aplicações (adaptado de [6]).

seca e via úmida [8]. Como exemplo, a argila encontrada na formação Corumbataí, na região de Santa Gertrudes - SP, possui propriedades de plasticidade privilegiadas, o que permite moagem a seco e um tempo de queima menor, elevando os índices de produtividade e reduzindo os custos. Por outro lado, o feldspato adequado a esta produção é frequentemente trazido do Nordeste (Paraíba e Rio Grande do Norte), elevando os custos locais de produção [9]. Neste cenário, a região de Poços de Caldas - MG apresenta-se como uma potencial fonte de matérias-primas às indústrias cerâmicas de pisos e revestimentos, louças de mesa, sanitários, entre outros, despontando-se como área promissora no fornecimento de substituintes cerâmicos a caulim, argilas e feldspatos em formulações cerâmicas.

O maciço alcalino de Poços de Caldas (MAPC), localizado na fronteira entre os estados de Minas Gerais e São Paulo, é um dos maiores maciços alcalinos ígneos do mundo, cobrindo mais de $800 \mathrm{~km}^{2}$, estando atrás apenas do maciço alcalino de Khibina $\left(1350 \mathrm{~km}^{2}\right)$, na península de Kola, extremo norte da Rússia europeia [10].

O MAPC é constituído principalmente por fonolitos e seus homólogos vulcânicos e plutônicos (tinguaítos e nefelino-sienitos), formando uma suíte félsica [10]. Ele vem sendo estudado no Brasil desde a década de $30 \mathrm{e}$, do ponto de vista tecnológico, o interesse tradicional se prende ao grande e variado número de depósitos, destacando-se os depósitos de argilominerais com massas homogêneas de caulinita, mica e gibsita, e depósitos de bauxito, ambos provenientes da alteração das rochas alcalinas do planalto [11]. Entretanto, por apresentar propriedades semelhantes ao feldspato, bem como possuir um elevado teor de alumina, a rocha potássica e o fonolito do MAPC são potenciais substitutos do feldspato na indústria cerâmica, sendo a rocha potássica fruto do metassomatismo hidrotermal, última etapa do magmatismo alcalino da região. Há enorme disponibilidade destas matérias-primas (> $500 \mathrm{Mt}$ ), com reservas sendo exploradas desde a década de 70 . A grande quantidade de álcalis presente confere caráter fundente e possibilita a sinterização das peças cerâmicas em temperaturas mais baixas. Em adição, tais matérias-primas encontram também aplicação na indústria vidreira. Contudo, a presença de óxidos de ferro pode ser um entrave para algumas aplicações, pois podem produzir coloração indesejada para as peças se o intuito for decorativo. $\mathrm{O}$ mesmo acontece quando se substitui o caulim por outras fontes de argila mais ricas em ferro e titânio, na tentativa de se criar uma massa cerâmica da classe porcelana, uma vez que esses óxidos alteram sua coloração para tons mais escuros [12]. As principais diferenças químicas entre a rocha potássica e o fonolito residem nos teores dos óxidos de sódio e potássio, sendo o fonolito mais rico em sódio e a rocha potássica rica em potássio. A soma destes óxidos gera um valor similar no total destes óxidos alcalinos.

A razão $\mathrm{Na}_{2} \mathrm{O} / \mathrm{K}_{2} \mathrm{O}$ influencia a temperatura de início de deformação, que está ligada à formação de fase líquida durante a sinterização. Quanto menor esta razão (maior proporção de potássio), maior a viscosidade da fase líquida para uma mesma temperatura [13].

Desta forma, torna-se interessante a análise das propriedades das massas cerâmicas secas em diferentes formulações, substituindo totalmente o feldspato por rocha potássica ou fonolito, e o caulim/argilas tradicionais por outras variedades de argilas, todos provenientes da região de Poços de Caldas.

\section{Materiais e Métodos}

Todas as matérias-primas utilizadas foram inicialmente secadas, britadas e moídas em moinho de bolas até que obtivessem granulometria passante na peneira ABNT 325 (diâmetro de abertura $=44 \mu \mathrm{m}$ ). De posse das matérias-primas preparadas, 04 formulações cerâmicas abaixo descritas (I, II, III e IV) foram desenvolvidas, visando avaliar potencialidades tecnológicas dos materiais alternativos de Poços de Caldas (PC). Objetivou-se manter uma formulação padrão que representasse o componente argila com $50 \%$ de percentual mássico, $25 \%$ para o componente quartzo e $25 \%$ para o componente feldspático. Assim, a única matéria-prima utilizada de origem externa à região de PC foi a areia de qualidade industrial, proveniente da região de Descalvado - SP (Mineração Jundu), representando o componente quartzo do triaxial cerâmico.

- I: $50 \%$ Argila Branca: Argila Amarela (1:1); $25 \%$ Areia; $25 \%$ Rocha Potássica.

- II: 50\% Argila Branca: Argila Amarela (1:1); $25 \%$ Areia; $25 \%$ Fonolito.

- III: 50\% Argila Bauxítica; 25\% Areia; 25\% Rocha Potássica.

- IV: 50\% Argila Bauxítica; 25\% Areia; 25\% Fonolito.

As matérias-primas e formulações tiveram suas composições químicas analisadas pela técnica de espectrometria de fluorescência de raios X (FRX) por dispersão de comprimento de onda (XRF 1800, Shimadzu), com preparação de amostras realizada pelo método da pérola de vidro em uma máquina automática de fusão operada sob alta frequência de indução (HA-HF 16/2, Herzog). As fases minerais foram identificadas por difratometria de raios X por pó (XRD 6000, Shimadzu), com radiação de cobre $(\mathrm{K} \alpha)$ e modo de varredura contínuo $\left(2^{\circ} / \mathrm{min}\right)$, num intervalo de 5 a $70^{\circ} 2 \theta$. 
Corpos de prova retangulares (paralelepípedos: $60 \times 20 \times 5 \mathrm{~mm}$ ) foram conformados através da preparação manual de uma mistura com teor de umidade de aproximadamente $6 \%$ (adição de $60 \mathrm{~g}$ de água em $1 \mathrm{~kg}$ de mistura, por meio de borrifador) e posterior prensagem uniaxial em molde metálico. A prensagem foi realizada sob uma força total de $200 \mathrm{kgf}$ na moldagem dos corpos. Esta magnitude é tipicamente utilizada na indústria de revestimentos cerâmicos para conformação dos produtos [14]. Os corpos de prova foram calcinados em fornos tipo mufla, com taxa de aquecimento de aproximadamente $20^{\circ} \mathrm{C} / \mathrm{min}$ e patamar de $2 \mathrm{~h}$, em 5 temperaturas máximas de tratamento térmico $\left(1.100,1.150,1.200,1.250\right.$ e $\left.1.300^{\circ} \mathrm{C}\right)$. Antes e após tratamento térmico, os corpos de prova foram medidos em paquímetro para determinação da retração linear (\%).

A medição de porosidade aparente dos corpos de prova tratados termicamente foi realizada com base no procedimento apresentado na norma ASTM 373-18 [15]. Para a pesagem da massa seca (D), os corpos de prova foram secados em estufa a $110^{\circ} \mathrm{C}$ por $2 \mathrm{~h}$. Para medir a massa suspensa em balança hidrostática (S) e a massa saturada em água $(\mathrm{M})$, as amostras foram completamente

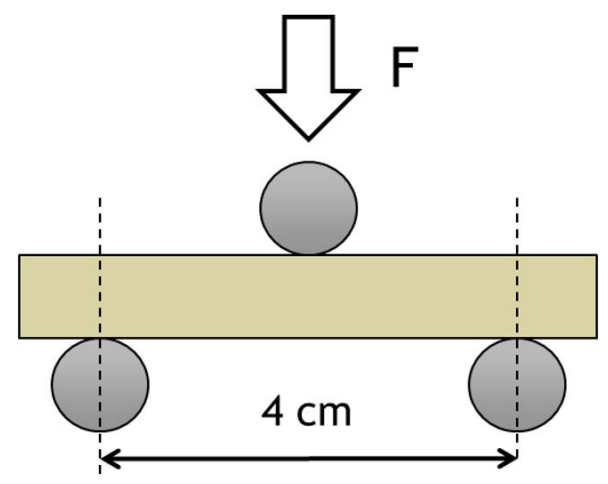

Figura 2. Esquema de ensaio de flexão em 3 pontos. imersas em água destilada sob fervor (3h), permanecendo em imersão por $24 \mathrm{~h}$. Os cálculos foram realizados de acordo com as seguintes equações (A-D):

$$
\begin{aligned}
& V=M-S \\
& P=\left[\frac{(M-D)}{V}\right] \cdot 100 \\
& A=\left[\frac{(M-D)}{D}\right] \cdot 100 \\
& B=D / V
\end{aligned}
$$

Onde, $\mathrm{D}=$ massa do corpo $\operatorname{seco}(\mathrm{g}) ; \mathrm{S}=$ massa do corpo imerso $(\mathrm{g}) ; \mathrm{M}=$ massa do corpo úmido $(\mathrm{g}) ; \mathrm{V}=$ volume aparente do corpo $(\mathrm{mL}) ; \mathrm{P}=$ porosidade aparente $(\%)$; $\mathrm{A}=$ absorção de água $(\%) ; \mathrm{B}=$ densidade bulk $\left(\mathrm{g} / \mathrm{cm}^{3}\right)$.

Os corpos de prova sinterizados tiveram sua resistência à flexão avaliadas por meio de um equipamento clássico para flexão em três pontos, com distância da base fixada a $4 \mathrm{~cm}$, conforme ilustrado na figura 2 . O cálculo do módulo de ruptura foi realizado conforme a equação $\mathrm{E}$, seguindo a norma ASTM C674 - 13 [16]:

$$
M O R=3 F \cdot L / 2 b \cdot d^{2}
$$

Onde, $\mathrm{MOR}=$ módulo de ruptura $(\mathrm{MPa}) ; \mathrm{F}=$ carga de ruptura $(\mathrm{N}) ; \mathrm{L}=$ distância entre os apoios $(\mathrm{mm})$; $\mathrm{b}=$ largura do corpo de prova $(\mathrm{mm}) ; \mathrm{d}=$ altura do corpo de prova $(\mathrm{mm})$.

\section{Resultados e Discussões}

\subsection{Análise química e mineralógica}

A tabela 1 mostra os resultados da análise química em base calcinada (AQ) de todas as matérias-primas (MP) e formulações cerâmicas estudadas.

Tabela 1. Análise química em base calcinada das matérias-primas (MABA, AB, RP, Fonolito e Areia) e formulações cerâmicas (I, II, III e IV).

\begin{tabular}{cccccccccc}
\hline $\mathbf{A Q} \mathbf{( \% )}$ & $\mathbf{M A B A}$ & $\mathbf{A B}$ & $\mathbf{R P}$ & Fonolito & Areia & I & II & III & IV \\
\hline $\mathrm{SiO}_{2}$ & 48,5 & 44,7 & 57,0 & 55,6 & 98,2 & 64,2 & 63,4 & 63,2 & 63,3 \\
$\mathrm{TiO}_{2}$ & 1,39 & 2,20 & 0,81 & 0,59 & 0,03 & 0,88 & 0,79 & 1,21 & 1,17 \\
$\mathrm{Fe}_{2} \mathrm{O}_{3}$ & 1,82 & 1,78 & 4,87 & 3,84 & 0,04 & 2,17 & 1,88 & 2,32 & 1,89 \\
$\mathrm{~K}_{2} \mathrm{O}$ & 2,05 & 3,41 & 13,6 & 8,77 & 0,00 & 4,53 & 3,18 & 5,16 & 3,82 \\
$\mathrm{Al}_{2} \mathrm{O}_{3}$ & 45,5 & 47,0 & 22,7 & 21,3 & 1,50 & 27,5 & 27,8 & 27,4 & 26,8 \\
$\mathrm{CaO}$ & 0,05 & 0,09 & 0,03 & 1,63 & 0,02 & 0,04 & 0,48 & 0,04 & 0,47 \\
$\mathrm{P}_{2} \mathrm{O}_{5}$ & 0,01 & 0,15 & 0,06 & 0,02 & 0,00 & 0,01 & 0 & 0,08 & 0,06 \\
$\mathrm{MnO}$ & 0,03 & 0,02 & 0,20 & 0,24 & 0,00 & 0,07 & 0,08 & 0,07 & 0,08 \\
$\mathrm{ZrO}$ & 0,28 & 0,34 & 0,13 & 0,16 & 0,06 & 0,18 & 0,19 & 0,21 & 0,21 \\
$\mathrm{MgO}_{2}$ & 0,09 & 0,13 & 0,06 & 0,25 & 0,00 & 0,07 & 0,12 & 0,08 & 0,13 \\
$\mathrm{Na}_{2} \mathrm{O}$ & 0,07 & 0,06 & 0,28 & 7,38 & 0,00 & 0,09 & 1,89 & 0,08 & 1,94 \\
$\mathrm{Cr}_{2} \mathrm{O}_{3}$ & 0,01 & 0,01 & 0,01 & 0,01 & 0,01 & 0,01 & 0,01 & 0,01 & 0,01 \\
\hline
\end{tabular}

MABA = Mistura de Argila Branca com Argila Amarela do planalto de Poços de Caldas, na razão mássica 1:1; $\mathrm{AB}=\mathrm{Argila}$

Bauxítica do Planalto de Poços de Caldas; RP = Rocha Potássica do Planalto de Poços de Caldas. 
A MP MABA(Mistura de Argila Branca com Amarela, na proporção mássica $1: 1)$ apresenta baixos teores para os óxidos de titânio $(1,39 \%)$, ferro $(1,82 \%)$ e potássio $(2,05 \%)$, e valores equilibrados para sílica $(48,5 \%)$ e alumina $(45,5 \%)$.

A argila bauxítica $(\mathrm{AB})$ também possui valores equilibrados em sílica $(44,7 \%)$ e alumina $(47,0 \%)$, sendo o teor de alumina encontrado o mais alto dentre as MP de PC aqui estudadas. Esta MP também apresentou o menor teor em óxido de ferro $(1,78 \%)$ e maior teor em óxido de titânio $(2,20 \%)$.

A rocha potássica (RP) apresenta os maiores teores em sílica $(57,0 \%)$ e potassa $(13,6 \%)$, e a amostra avaliada também apresentou os maiores teores em óxido de ferro $(4,87 \%)$. No entanto, é possível localizar na região áreas com teores mais reduzidos em ferro e potássio.

O fonolito do MAPC destaca-se pela alta homogeneidade oriunda da sua formação e pronunciada fusibilidade (ação fluxante), que está associada aos altos teores de óxido de sódio $(7,38 \%)$, teores apreciáveis de potássio $(8,77 \%)$ e presença de cálcio (1,63\%). Em relação à alumina (21,3\%), o fonolito apresentou o teor mais baixo dentre as MPs.

Todas as formulações (I, II, III e IV) apresentaram teores mássicos similares em sílica $(\sim 63 \%)$ e alumina ( $27 \%)$. As formulações II e IV, em que foi utilizado fonolito como componente feldspático, diferenciaram-se pelos maiores teores em cálcio $(\sim 0,5 \%)$ e sódio $(\sim 2,0 \%)$, sendo que as amostras com rocha potássica (I e III) apresentaram teores menores que $0,1 \%$ para estes óxidos.

$\mathrm{O}$ óxido que mais sofreu variação individualmente entre as quatro formulações trabalhadas foi o de potássio, com mínimo de 3,18\% para a formulação II e máximo de $5,16 \%$ para a composição III. Estes teores, assim como os demais, estão coerentes com o apresentado na análise das matérias-primas individuais, e suas contribuições em cada formulação.

A presença de óxidos de ferro em um teor mássico de aproximadamente $2 \%$ para as quatro composições causou uma coloração com tons um pouco mais escuros nas amostras com fonolito (II e IV) sinterizadas a partir de $1.150^{\circ} \mathrm{C}$, e nas amostras com rocha potássica (I e III) sinterizadas a partir de $1.250^{\circ} \mathrm{C}$.

$\mathrm{Na}$ análise mineralógica por difração de raios $\mathrm{X}$ (DRX), o único mineral identificado para a areia industrial foi o quartzo $\left[\mathrm{SiO}_{2}\right]$, em concordância ao elevado teor de sílica presente $(>98 \%)$. Para as demais formulações, foi possível identificar 02 fases na rocha potássica (RP), 03 na mistura de argilas branca e amarela (MABA), 07 na argila bauxítica (AB), e também 07 no fonolito. Destaque para o argilomineral caulinita como fase principal na MP MABA, e o feldspato potássico microclínio como fase majoritária na RP. A figura 3 apresenta os difratogramas com as fases minerais identificadas para as matérias-primas da região de Poços de Caldas (PC), e a descrição das fórmulas químicas de cada mineral em legenda.

\subsection{Propriedades físicas}

Após tratamento térmico das 04 composições em 05 temperaturas diferentes, avaliou-se a retração linear (RL), densidade bulk (B), absorção de água (A) e módulo de ruptura (MOR) dos corpos formados. A figura 4 apresenta um perfil comparativo destas propriedades físicas.

De forma geral, ao examinarmos as amostras contendo fonolito em sua formulação (II e IV), observa-se uma semelhança no perfil das curvas dos gráficos, mostrando uma tendência a formar um patamar a partir da temperatura

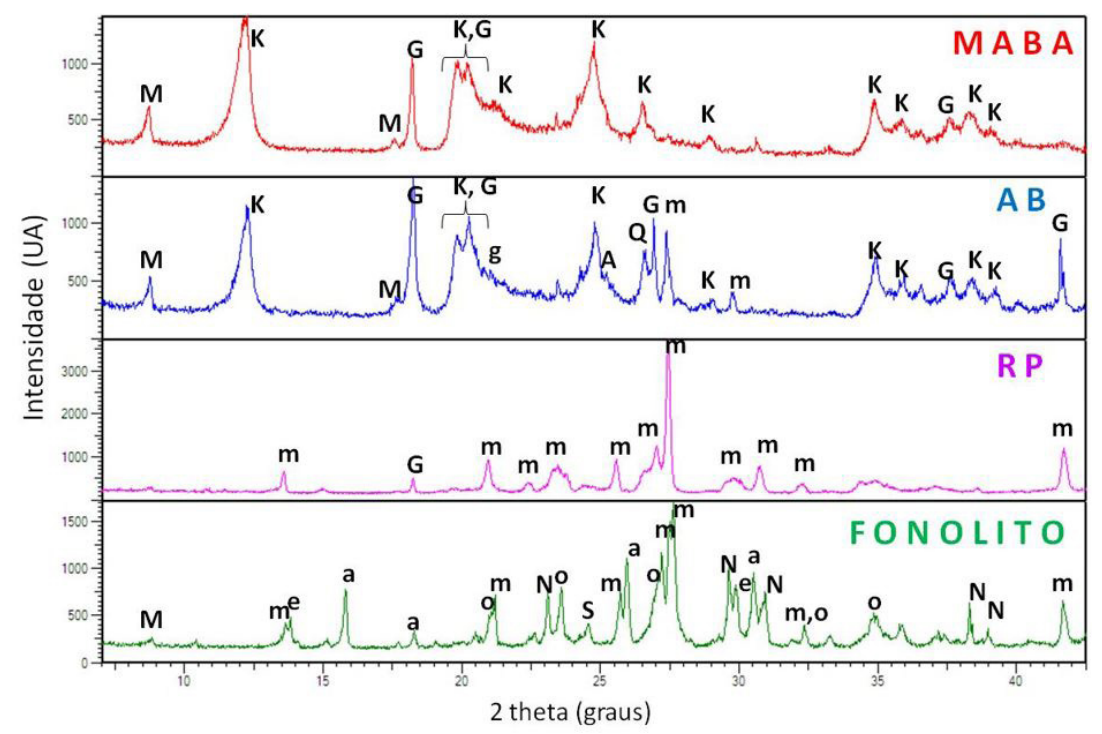

Figure 3. Difratograma de raios $\mathrm{X}$ e identificação mineralógica das matérias-primas da região de PC utilizadas nas formulações cerâmicas. $\mathrm{M}=$ Muscovita $\left[\mathrm{KAl}_{3} \mathrm{Si}_{3} \mathrm{O}_{10}(\mathrm{OH})_{2}\right] ; \mathrm{K}=$ Caulinita $\left[\mathrm{Al}_{2} \mathrm{Si}_{2} \mathrm{O}_{5}(\mathrm{OH})_{4}\right] ; \mathrm{G}=$ Gibsita $\left[\mathrm{Al}(\mathrm{OH})_{3}\right] ; \mathrm{g}=\mathrm{Goetita}[\mathrm{FeO}(\mathrm{OH})]$; $\mathrm{A}=$ Anatásio $\left[\mathrm{TiO}_{2}\right] ; \mathrm{Q}=$ Quartzo $\left[\mathrm{SiO}_{2}\right] ; \mathrm{m}=$ Microclínio $\left[\mathrm{KAlSi}_{3} \mathrm{O}_{8}\right] ; \mathrm{e}=$ Aegirina $\left[\mathrm{NaFe}\left(\mathrm{Si}_{2} \mathrm{O}_{6}\right)\right] ; \mathrm{a}=\operatorname{Analcima}\left[\mathrm{Na}\left(\mathrm{AlSi} \mathrm{O}_{6}\right)\right.$. $\left.\mathrm{H}_{2} \mathrm{O}\right] ; \mathrm{o}=$ Ortoclásio [ $\left.\mathrm{KAlSi}_{3} \mathrm{O}_{8}\right] ; \mathrm{N}=$ Nefelina $\left[\mathrm{KNa}_{3} \mathrm{Al}_{4} \mathrm{Si}_{4} \mathrm{O}_{16}\right] ; \mathrm{S}=$ Sodalita $\left[\mathrm{NaAl}_{3} \mathrm{Si}_{3} \mathrm{O}_{12} \mathrm{Cl}\right]$. 

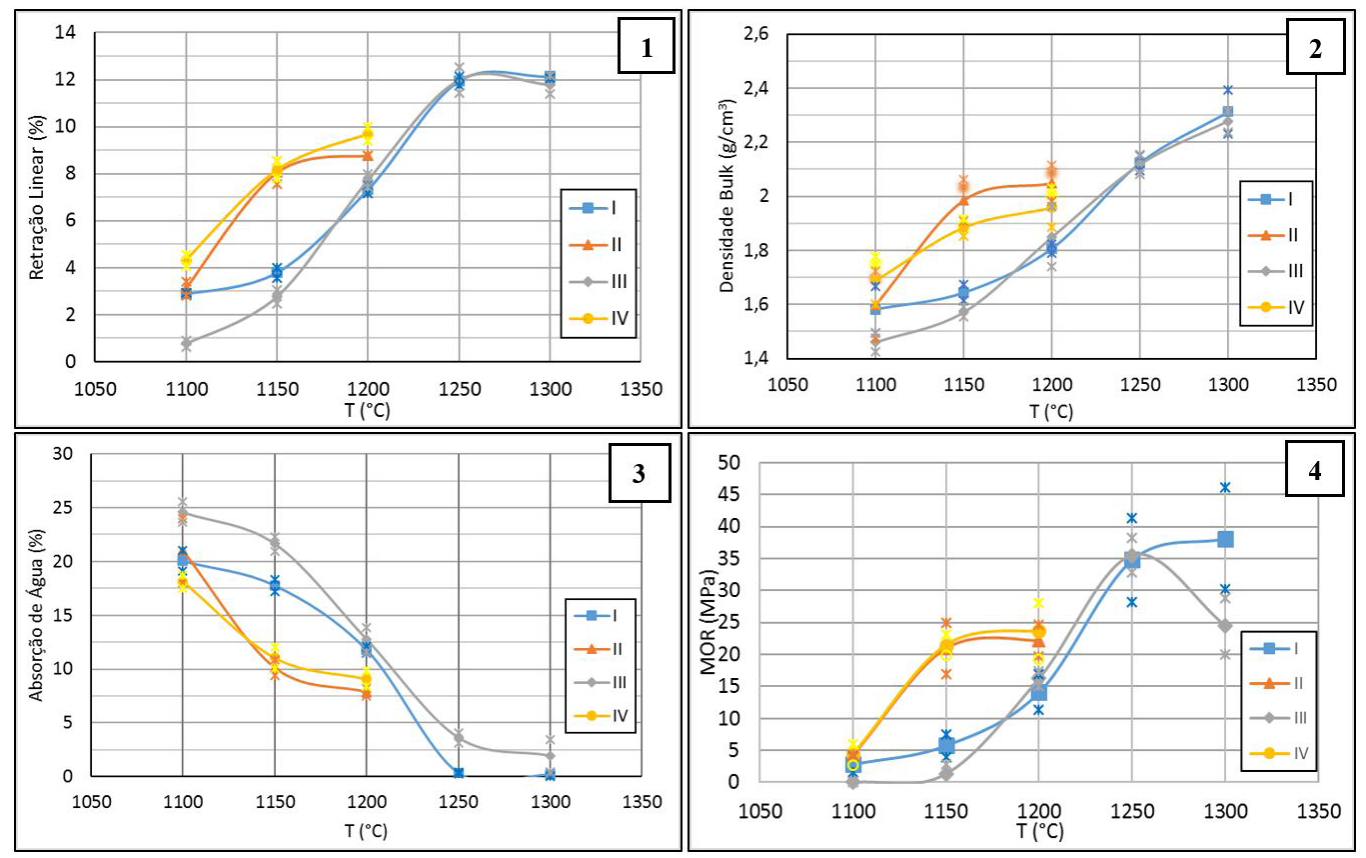

Figura 4. Gráficos de propriedades físicas: 1 = Retração linear (RL); 2 = Densidade bulk (B); 3 = Absorção de água (A); 4 = Módulo de ruptura (MOR).

de tratamento térmico em $1.200^{\circ} \mathrm{C}$. A estabilização destes parâmetros físicos com o aumento da temperatura indica o alcance do ponto de sinterização da composição. Em adição, tais amostras apresentaram sinais de vitrificação (defeitos) na face dos paralelepípedos nas temperaturas de 1.150 e $1.200^{\circ} \mathrm{C}$, detectado por pequenos pontos circulares e escuros ("bolhas"), o que fez com que as sinterizações a temperaturas superiores fossem evitadas a fim de prevenir amolecimento dos paralelepípedos e reação com o revestimento refratário do forno. Esses defeitos estão ligados à redução de viscosidade na fase líquida, causada pela maior concentração de sódio, que positivamente reduziu a temperatura de sinterização da peça, mas em contrapartida apresentou piores propriedades em temperaturas mais elevadas, muito provavelmente associado ao excesso deste componente na composição.

Referidos defeitos também ocorreram nas amostras contendo rocha potássica como componente feldspático em sua formulação (I e III), no entanto, apenas passaram a ser perceptíveis a partir de $1.250^{\circ} \mathrm{C}$, confirmando a teoria que correlaciona a razão $\mathrm{Na}_{2} \mathrm{O} / \mathrm{K}_{2} \mathrm{O}$ com a viscosidade do líquido formado. Em adição, a tendência à formação de um patamar com o aumento de temperatura de tratamento térmico só pôde ser observada ao executar-se a calcinação à $1.300^{\circ} \mathrm{C}$, onde melhores propriedades foram obtidas. Nota-se que esta tendência é observada para todas as 04 propriedades físicas estudadas, com exceção apenas do módulo de ruptura na formulação III, que demonstrou uma queda à $1.300^{\circ} \mathrm{C}$ (figura 4.4). Um dos fatores que levaram a formulação I ter desempenho superior em relação à formulação III reside no componente argiloso utilizado. A formulação I utilizou uma mistura de argilas (MABA) em que o principal mineral é a caulinita, que viabiliza a formação de mulita em temperaturas mais baixas, gerando também uma melhor densificação durante a sinterização. Por outro lado, a formulação III utilizou uma argila bauxítica com maior presença da fase gibsita e muito provavelmente em excesso na formulação, ocasionando microtrincas na peça sinterizada decorrente de expansão térmica na formação de mulita secundária e fragilizando o material [17-19]. Tal argumento é bastante válido, uma vez que também se nota uma pequena redução na retração linear (figura 4.1), menor densidade bulk (figura 4.2), e valores mais altos de absorção de água (figura 4.3). Dessa forma, pode-se inferir que essas microtrincas ocasionaram maior porosidade aberta e redução da resistência mecânica. No geral, observa-se melhores resultados para a formulação I, em que nas temperaturas de 1.250 e $1.300^{\circ} \mathrm{C}$ obteve-se excelente redução na absorção de água $(\mathrm{A}<0,5 \%)$, valores adequados de densidade $\left(\mathrm{B}=2,12 \mathrm{e} 2,31 \mathrm{~g} / \mathrm{cm}^{3}\right)$ e ótimos valores de resistência mecânica (MOR $=34,8$ e 38,2 MPa).

\section{Conclusão}

As argilas do planalto de Poços de Caldas, assim como a rocha potássica e o fonolito, apresentam potencialidades de aplicação tecnológica nas formulações de porcelanas e materiais de revestimentos:

- A formulação cerâmica que utilizou uma massa seca moída (\# 325) contendo 50\% em mistura de argila branca e amarela (1:1), $25 \%$ de areia industrial e $25 \%$ de rocha potássica, apresentou boas propriedades após prensagem e tratamento térmico sob duas temperaturas: $1.250^{\circ} \mathrm{C}(\mathrm{A}=0,35 \%$; 
$\mathrm{B}=2,12 \mathrm{~g} / \mathrm{cm}^{3}$ e $\left.\mathrm{MOR}=34,8 \mathrm{MPa}\right)$ e $1.300^{\circ} \mathrm{C}$ $\left(\mathrm{A}=0,21 \% ; \mathrm{B}=2,31 \mathrm{~g} / \mathrm{cm}^{3}\right.$ e $\left.\mathrm{MOR}=38,2 \mathrm{MPa}\right)$.

- A rocha potássica e o fonolito apresentaram bom caráter fundente em formulações com $25 \%$ em massa, com as amostras contendo fonolito alcançando temperaturas de sinterização mais baixas, sendo ambos potenciais substituintes ao feldspato tradicional.

\section{Agradecimentos}

Os autores agradecem ao Grupo Curimbaba pelo apoio neste projeto, e ao prof. Dr. Rer. Nat. José de Anchieta Rodriguez pela parceria entre a universidade (UFSCar) e a empresa (Mineração Curimbaba Ltda).

\section{Referências}

[1] KELLY, J. R.; NISHIMURA, I.; CAMPBELL S. D. Ceramics in dentistry: Historical roots and current perspectives. The Journal of Prosthetic Dentistry, v. 75, n.1, p. 18-32, 1996.

[2] DE NONI JR, A. et al. Influence of composition on mechanical behaviour of porcelain tile. Part I: Microstructural characterization and developed phases after firing. Materials Science and Engineering, A, v. 527, n. 7-8, p. 1730-1735, 2010.

[3] CRAIG, R. G. Materiais dentários restauradores, $11^{\mathrm{a}}$ Ed., Ed. Santos, S. Paulo, SP (2004) 575.

[4] BRAGANCA, S. R.; BERGMANN, C. P.; Microestrutura e propriedades de porcelanas. Cerâmica. Vol. 50, n. 316 (out/ dez. 2004), p. 291-299, 2004.

[5] RUIZ, M. S. et al. A Indústria de Louça e Porcelana de Mesa no Brasil. Cerâmica Industrial, v. 16, n. 2, p. 29-34, 2011.

[6] ROMERO, M.; PÉREZ, J. M. Relation between the microstructure and technological properties of porcelain stoneware. A review. Materiales de Construcción, v. 65, n. 320, p. 065, 2015.

[7] PRADO, U. D.; BRESSIANI, J. C.; Panorama da indústria cerâmica brasileira na última década. Cerâmica Industrial, v. 18, n. 1, p. 7-11, 2013.

[8] Associação Nacional dos fabricantes de Cerâmica para Revestimentos, Louças e Congêneres. Panorama 2018 -
Cerâmicas do Brasil Revestimentos e Louças Sanitárias, ANFACER \& ApexBrasil (2018) 72.

[9] CRUZ, C. M. et al. Uso de nefelina como fonte alternativa de álcalis em porcelanatos: caracterização reológica e física. Cerâmica, v. 64, p. 230-235, 2018.

[10]ULBRICH, H. H. et al. Structure and Origin of the Poços de Caldas Alkaline Massif, SE Brazil; In: Mesozoic to Cenozoic Alkaline Magmatism in the Brazilian Platform / P. Comin-Chiaramonti and C. B. Gomes (editors). São Paulo: editora da Universidade de São Paulo: Fapesp, 2005.

[11] MONIZ, A. C. Estudo mineralógico de argilas do maciço alcalino de Poços de Caldas [doi:10.11606/T.44.2016.tde29082016-143600]. São Paulo: Instituto de Geociências, Universidade de São Paulo, 1964. Tese de Doutorado em Mineralogia e Petrologia. [acesso 2018-12-14].

[12] PAVLOV, V. F.; MESHCHERYAKOVA, I. V. Reducing the coloring effects of iron oxides in porcelain bodies. Glass and Ceramics, v. 40, n. 3, p. 150-152, 1983.

[13] TAMSU, N.; VEDAT BAYRAK, A.; OZDEMIR, H. Effects of $\mathrm{Na} 2 \mathrm{O} / \mathrm{K} 2 \mathrm{O}$ Ratio on the Deformation Behaviour of the Floor Tile Bodies. Acta Physica Polonica, A., v. 123, n. 2, 2013.

[14] JUNIOR, J. S. et. al. Reciclagem de rejeitos de pisos cerâmicos esmaltados, CBECIMAT, Natal, 2002.

[15] American Society for Testing and Materials. ASTM C373 - 18: Standard Test Methods for Determination of Water Absorption and Associated Properties by Vacuum Method for Pressed Ceramic Tiles and Glass Tiles and Boil Method for Extruded Ceramic Tiles and Non-Tile Fired Ceramic Whiteware Products.

[16] American Society for Testing and Materials. ASTM C674 - 13: Standard Test Methods for Flexural Properties of Ceramic Whiteware Materials.

[17] MAGAGNIN, D. et al. Effect of kaolinite, illite and talc on the processing properties and mullite content of porcelain stoneware tiles. Materials Science and Engineering, A, v. 618, p. 533-539, 2014.

[18] MAGLIANO, M. V. M.; PANDOLFELLI, V. C. Mulitização em refratários utilizando diferentes fontes precursoras-revisão. Cerâmica, v. 56, p. 368-375, 2010.

[19] PASCOAL, C., PANDOLFELLI, V. C. Bauxitas Refratárias: Composição química, fases e propriedades - Parte II. Cerâmica, v. 46, n. 299, p. 131-138, 2000. 